\title{
Supramolecular Pattern of Fullerene on 2D Bimolecular 'Chessboard' Consisting of Bottom-up Assembly of Porphyrin and Phthalocyanine Molecules
}

\author{
Soichiro Yoshimoto, ${ }^{*,+}$, Yosuke Honda, ${ }^{\dagger}$ Osamu Ito, ${ }^{\ddagger}$ Kingo Itaya ${ }^{*, \dagger}$
}

\footnotetext{
${ }^{\dagger}$ Department of Applied Chemistry, Graduate School of Engineering, Tohoku University 6-6-07 Aoba, Sendai 980-8579 (Japan).

₹Institute of Multidisciplinary Research for Advanced Materials, Tohoku University Katahira, Aoba-ku, Sendai 980-8577 (Japan).

${ }^{\S}$ Present address: National Institute of Advanced Industrial Science and Technology (AIST) Central 6, 1-1-1 Higashi, Tsukuba, Ibaraki 305-8566 (Japan).
} 
Figure S1.

(a)

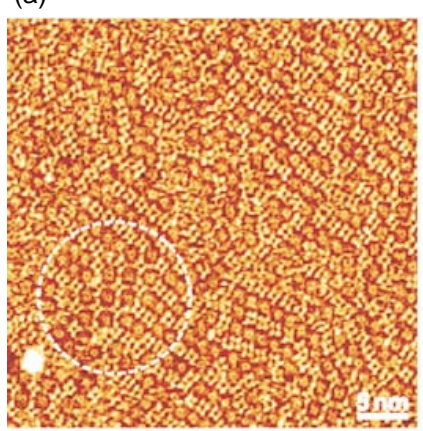

(b)

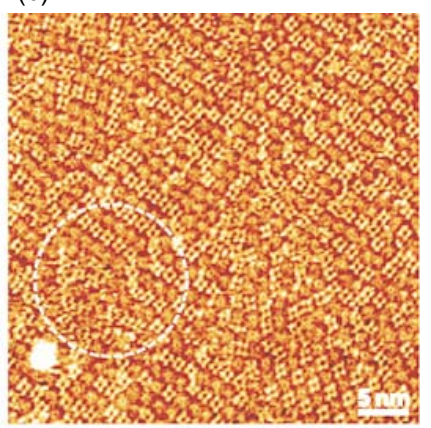

Figure S1. Time-dependent STM images $\left(40 \times 40 \mathrm{~nm}^{2}\right)$. The circled areas in the two panels show images of the same area. The bifunctional $\mathrm{ZnPc}$ and $\mathrm{ZnOEP}$ adlayer on $\mathrm{Au}(111)$ in $0.1 \mathrm{M}$ $\mathrm{HClO}_{4}$ was acquired at $0.60 \mathrm{~V}$ vs. RHE. The STM image (b) was taken $10 \mathrm{~min}$ after image (a) was recorded. Tip potential was $0.20 \mathrm{~V}$ for both (a) and (b), and tunneling currents were $1.72 \mathrm{nA}$ for (a) and $1.35 \mathrm{nA}$ for (b). 
Figure S2.

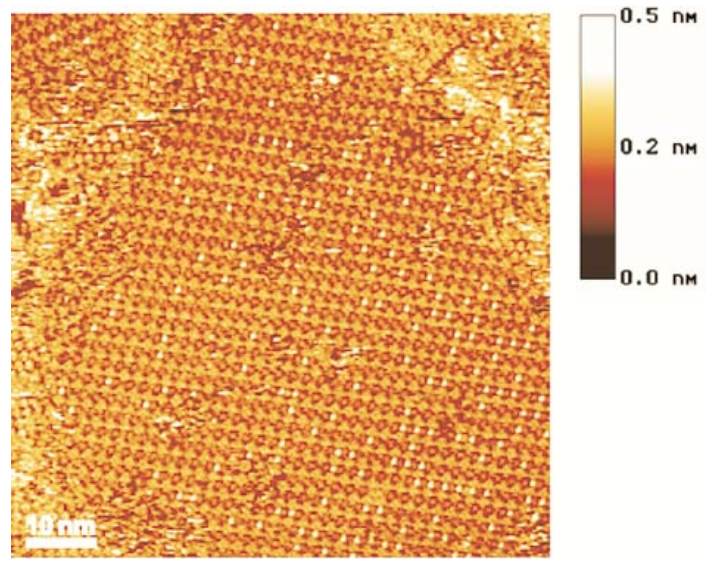

Figure S2. Large-scale $\left(75 \times 75 \mathrm{~nm}^{2}\right)$ STM image of $\mathrm{C}_{60}$ arrays on the bimolecular chessboard in $0.1 \mathrm{M}$ $\mathrm{HClO}_{4}$ obtained at $0.75 \mathrm{~V}$ vs. RHE. Tip potential and tunneling current were $0.27 \mathrm{~V}$ and $0.75 \mathrm{nA}$, respectively. 
Figure S3

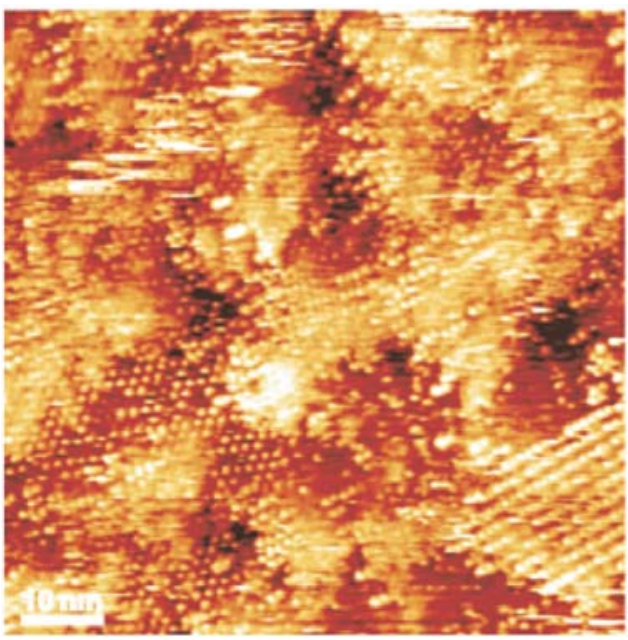

Figure S3. Typical large-scale $\left(75 \times 75 \mathrm{~nm}^{2}\right)$ STM image of $\mathrm{C}_{60}$ arrays on the bimolecular $\mathrm{ZnPc}$ and ZnOEP adlayer in $0.1 \mathrm{M} \mathrm{HClO}_{4}$ obtained at $0.83 \mathrm{~V}$ vs. RHE. Tip potential and tunneling current were $0.27 \mathrm{~V}$ and $0.23 \mathrm{nA}$. In the STM image, hexagonally-arranged $\mathrm{C}_{60}$ array formed on pure ZnOEP domain (lower left portion) and squarely-arranged $\mathrm{C}_{60}$ array formed on the nanochessboard (lower right portion) are seen, whereas poorly defined regions were observed in the upper area. 